\title{
ĐÁNH GIÁ NGUY CƠ BỊ TỔN THUOONNG DO SÓNG THẦN CHO KHU VỬC ĐÔ THI THÀNH PHỐ NHA TRANG
}

\author{
NGUYẼ̃N HỒNG PHƯƠNG ${ }^{1}$, PHẠM THẾ TRUYÊN ${ }^{1}$, ADRIEN MOIRET $^{2}$ \\ E-mail: phuong.dongdat@gmail.com \\ ${ }^{1}$ Viện Vật lý Địa cầu, Viện Khoa họ và Công nghệ Việt Nam, \\ ${ }^{2}$ Université Paris Est - Marne la vallée - Institut Francilien des Sciences Appliquées (IFSA)
}

Ngày nhận bài: 06-9-2010

\section{Mở đầu}

Ở Việt Nam, mặc dù công trình nghiên cứu đầu tiên về sóng thần đã được công bố từ năm 1995, hướng nghiên cứu sóng thần vẫn không được phát triển mạnh do tính thời sự của vấn đề tại thời điểm đó chưa cao [7]. Sau thảm họa động đất sóng thần Ấn Độ Dương ngày 26 tháng 12 năm 2004, cùng với sự đổi mới căn bản về nhận thức của cộng đồng và nhiều quốc gia trong khu vực về sức mạnh hủy diệt của loại hình thiên tai này, việc nghiên cứu sóng thần ở Việt Nam mới có được sự chuyển mình mạnh mẽ. Trong thời gian này, đã có rất nhiều đề tài nghiên cứu được triển khai thực hiện với sự tham gia của đông đảo các chuyên gia và các nhà khoa học thuộc nhiều lĩnh vực liên quan. Nội dung và số lượng của các công trình nghiên cứu sóng thần ở Việt Nam cho đến thời điểm này là khá đa dạng và có thể phân thành ba nhóm chính. Nhóm thứ nhất là các công trình nghiên cứu đánh giá độ nguy hiểm sóng thần cho các vùng bờ biển và hải đảo Việt Nam trên cơ sở phân tích các đặc trưng về tính địa chấn và kiến tạo - địa động lực khu vực Đông Nam Á đóng vai trò quyết định trong cơ chế hình thành và phát sinh sóng thần trên khu vực Biển Đông Việt Nam. Kết quả tiêu biểu nhất của các công trình nghiên cứu thuộc nhóm này là các bản đồ chỉ rõ vị trí và ranh giới các vùng nguồn phát sinh động đất có khả năng gây ra sóng thần ảnh hưởng trực tiếp tới các vùng bờ biển và hải đảo của Việt Nam và mức độ nguy hiểm cực đại mà các trận sóng thần này có thể gây ra. Đó là các công trình nghiên cứu khoa học của Nguyễn Đình Xuyên và cộng sự (2007), Trần Thị Mỹ Thành và cộng sự (2009), Nguyễn Hồng Phương và cộng sự (2009) và Bùi Công Quế và cộng sự (2010) [4-6, 8]. Nhóm thứ hai là các công trình nghiên cứu mô phỏng sự lan truyền của sóng thần từ các vùng nguồn đến các vùng bờ biển và hải đảo của Việt Nam. Tiêu biểu nhất cho các nghiên cứu thuộc loại này là đề tài nghiên cứu của Vũ Thanh $\mathrm{Ca}$ và cộng sự (2008). Nghiên cứu này sử dụng các nghiên cứu của nhóm thứ nhất, cụ thể là các tham số nguy hiểm địa chấn của các vùng nguồn trên khu vực Biển Đông và lân cận để mô phỏng các kịch bản sóng thần trên Biển Đông. Kết quả của nghiên cứu này là một cơ sở dữ liệu chứa 25 kịch bản sóng thần tính sẵn và tập bản đồ cảnh báo nguy cơ sóng thần cho các vùng ven biển và hải đảo của Việt Nam [1].

Cần nhận xét rằng các nghiên cứu thuộc hai nhóm nêu trên mới chỉ đề cập tới việc đánh giá độ nguy hiểm sóng thần, tức là chỉ ra những khu vực có khả năng bị sóng thần tấn công với xác suất cao nhất trên toàn dải ven biển và hải đảo của Việt Nam. Trong khi đó, một nội dung khác, không kém phần quan trọng vẫn còn chưa được đề cập đến một cách đầy đủ trong các nghiên cứu về sóng thần ở Việt nam cho đến nay. Đó là việc dự báo mức độ thiệt hại mà sóng thần có thể gây ra cho cộng đồng tại các khu vực đô thị hay các khu vực trọng điểm thuộc dải ven biển và hải đảo của Việt Nam. Các nghiên cứu theo hướng này có thể đưa vào nhóm thứ ba: nhóm các nghiên cứu đánh giá rủi ro do sóng thần.
Formatted: Font: $11 \mathrm{pt}$

Formatted: Position: Horizontal: Inside, Relative to: Margin

Formatted: Indent: First line: 0.63 
Bài viết này trình bày một nghiên cứu mới thuộc hướng thứ ba theo cách phân loại trên đây. Mục đích chính của nghiên cứu này là xây dựng một phương pháp luận đánh giá nguy cơ bị tổn thương do sóng thần gây ra cho một khu vực đô thị nằm trên dải ven biển của Việt Nam. Phương pháp luận được áp dụng thử nghiệm cho thành phố Nha Trang, với sự trợ giúp của công cụ GIS trong việc xây dựng cơ sở dữ liệu, tính toán và thể hiện các kêt quả.

\section{Mức độ tổn thương do sóng thần và các khái} niệm liên quan

Hiểm họa sóng thần thường tập trung cao nhất tai các khu vực nằm sát bờ biển và có thể trở thành thảm họa nếu khu vực đó đồng thời cũng là một khu vực phát triển của cộng đồng. Ở Việt Nam, mặc dù chưa có tài liệu chính thức nào được công bố về thiệt hại do sóng thần gây ra trong quá khứ, song các kết quả nghiên cứu đều cho thấy khu vực miền Trung đất nước được đánh giá là có độ nhạy cảm cao đối với hiểm hoạ sóng thần $[1,4,8]$. Đối với những khu vực như vậy, việc đánh giá độ rủi ro sóng thần nhằm đề xuất những biện pháp phòng ngừa và giảm thiểu những tổn thất do động đất gây ra đối với cộng đồng là một việc làm không những mang tính thiết thực, mà còn vô cùng cấp bách.

Phương pháp luận đánh giá rủi ro và giảm nhẹ thiệt hại do sóng thần gây ra cho một khu vực đô thị thường được xây dựng dựa trên ba khái niệm co bản nhất, bao gồm: Độ rủi ro sóng thần, Độ nguy hiểm sóng thần và Mức độ tổn thương do sóng thần sẽ được định nghĩa dưới đây.

Độ rủi ro sóng thần là xác suất xẩy ra những tổn thất về kinh tế xã hội do sóng thần gây ra tại một khu vực cho trước, trong một khoảng thời gian cho trước.

Độ nguy hiểm sóng thần là xác suất xuất hiện của một cơn sóng thần có thể gây thiệt hại cho một vùng cho trước trong một khoảng thời gian cho trước. Trong các tính toán định lượng, độ nguy hiểm sóng thần thường được gán bằng các giá trị độ cao sóng thần khi tấn công vào bờ hay độ sâu ngập lụt do sóng thần.

Mức độ tổn thương do sóng thần là khả năng bị mât mát hay khả năng ứng phó của cộng đồng đô thị ven biển khi bị đặt trước sự đe dọa của tai biến sóng thần. Mức độ bị tổn thương thường được xét tương ứng với các yếu tố chịu rủi ro. Ở đây các yếu tố chiu rủi ro được hiểu là tất cả các đối tượng có mặt trên khu vực nghiên cứu, bao gồm cả những đối tượng trực tiếp của sóng thần như con người, nhà cửa và các hệ thống giao thông, thông tin liên lạc, hay gián tiếp như những tổn thất về kinh tế hay xã hội.

Độ rủi ro sóng thần, độ nguy hiểm sóng thần, mức độ tổn thương và yêu tô chịu rủi ro do sóng thần liên hệ với nhau bởi biểu thức:

$$
R=H \sum_{i}^{n} E_{i} V_{i}
$$

ở đây $\mathrm{E}$ là yếu tố chịu rủi ro; $\mathrm{V}$ là khả năng bị tổn thương, biểu thị số đo của những tổn thất thành phần; và $\mathrm{H}$ là độ nguy hiểm sóng thần. Chỉ số $\mathrm{i}$ biểu thị loại yếu tố chịu rủi ro.

\section{Xây dựng phương pháp luận đánh giá mức độ tổn thương do sóng thần}

Đã có nhiều công trình nghiên cứu về đánh giá nguy cơ bị tổn thương do sóng thần cho các khu vực khác nhau trên thế giới $[2,3,10]$. Phần lớn các nghiên cứu này đều sử dụng kỹ thuật phân tích đa tiêu chuẩn (Multi-criteria analysis) để xây dựng phương pháp luận đánh giá khả năng bị tổn thương. Đây là một kỹ thuật được áp dụng khá phổ biến trong các quá trình ra quyết định, với nội dung chính bao gồm việc xác định các mục tiêu cần đạt và phân tích tổ hợp các tiêu chuẩn khác nhau để đưa ra phương án tối ưu cho quyết định cuối cùng [9].

Trong nghiên cứu được các tác giả trình bày trong bài viết này, phương pháp đánh giá khả năng bị tổn thương do sóng thần được xây dựng trên cơ sở tham khảo và cải tiến các phương pháp đang được sử dụng cho phù hợp với điều kiện Việt Nam, đặc biệt lưu ý tới khả năng áp dụng công nghệ GIS để tính toán và hiển thị các kết quả nhận được.

\subsection{Công thức tính mức độ tổn thương}

Công thức tổng quát tính mức độ tổn thương do sóng thần có dạng:

$$
V\left(a_{i}, A\right)=\sum_{i}^{n} w_{i} e_{i}, \mathrm{i}=1, \mathrm{n}
$$

trong đó $\mathrm{V}$ là số đo mức độ tổn thương; $\mathrm{A}$ là tham số tổn thương; $\mathrm{a}_{\mathrm{i}}$ là các yếu tố ảnh hưởng; $\mathrm{w}_{\mathrm{i}}$ là trọng số của yếu tố ảnh hưởng thứ $i$; $\mathrm{e}_{\mathrm{i}}$ là giá trị ước lượng cho yếu tố ảnh hưởng thứ $i$; và $n$ là tổng số các yếu tố ảnh hưởng có liên quan tới tham số tổn thương $\mathrm{A}$.

Các tham số tổn thương đặc trưng cho các dạng thiệt hại khác nhau và được xác định theo các yếu
Formatted: Font: $11 \mathrm{pt}$

Formatted: Position: Horizontal: Inside, Relative to: Margin

Formatted: Indent: First line: 0.63 
tố chịu rủi ro. Ứng với mỗi tham số tổn thương $\mathrm{A}$, một danh sách các yếu tố ảnh hưởng $\mathrm{a}_{\mathrm{i}}$ được xác định. Các yếu tố này đặc trưng cho khả năng bị tác động nhiều nhất bởi sóng thần. Tổng hợp của những yếu tố ảnh hưởng sẽ xác định mức độ bị tổn thương của tham số đang xét.

Do khuôn khổ của bài viết, trong nghiên cứu này chỉ xét hai yếu tố chịu rủi ro quan trọng nhất đối với cộng đồng ven biển là: Tham số tổn thương "Nhà cửa" và Tham số tổn thương "Người".

\section{2. Đánh giá mức độ tổn thương cho tham số "Nhà của"}

Mức độ tổn thương về nhà cửa có thể được hiểu như là khả năng chống chọi với sóng thần của nhà cửa và các công trình xây dựng tại khu vực nghiên cứu. Đối với tham số "Nhà cửa", các yếu tố ảnh hưởng tương ứng được xác định bao gồm: Vật liệu xây dựng-m (material), Mô tả tầng trệt của ngôi nhà-g (description of ground floor), Số tầng- $\mathrm{s}$ (stories), Thiết kế-d (design), Kết cấu nền móng$\mathrm{f}$ (foundations).

Các tiêu chuẩn đánh giá biểu thị các dạng thiệt hại do sóng thần gây ra cho nhà cửa tại khu vực nghiên cứu. Đối với tham số "Nhà cửa", hai dạng thiệt hại được đánh giá bằng cách gán trọng số bao gồm: Thiệt hại về cấu trúc; và Thiệt hại do ngập lụt.

Quá trình gán trọng số cho các tiêu chuẩn đánh giá được thực hiện như sau. Đầu tiên, các tiêu chuẩn đánh giá được sắp xếp theo hàng và cột trong một ma trận và được so sánh lần lượt theo từng cặp để đánh giá sự phù hợp (bảng 1 ). Nếu giữa hai tiêu chuẩn đang được so sánh, tiêu chuẩn nào đó (nằm trên hàng) được cho là quan trọng hơn tiêu chuẩn đang được so sánh (nằm trên cột) thì ô nằm ở giao điểm giữa hàng và cột đó được gán 1 điểm. Trong trường hợp ngược lại, ô đó được gán 0 điểm. Yếu tố ngoại cảnh ở đây được sử dụng để bổ trợ cho quá trình tính toán. Bảng $l$ cho thấy thiệt hại về cấu trúc có trong số cao hơn so với thiệt hại do ngập lụt gây ra (0.667 so với 0.333$)$.

Bảng 1. Ma trận so sánh cặp đôi giữa các tiêu chuẩn đánh giá

\begin{tabular}{|c|c|c|c|c|c|}
\hline & $\begin{array}{l}\text { Thiệt hại về } \\
\text { cấu trúc }\end{array}$ & $\begin{array}{l}\text { Thiệt hại do } \\
\text { ngập lụt }\end{array}$ & $\begin{array}{c}\text { Yếu tố } \\
\text { ngoại cảnh khác }\end{array}$ & Tổng & Trọng số (= tổng/3) \\
\hline $\begin{array}{l}\text { Thiệt hại về } \\
\text { cấu trúc }\end{array}$ & - & 1 & 1 & 2 & 0.667 \\
\hline $\begin{array}{l}\text { Thiệt hại do } \\
\text { ngập lụt }\end{array}$ & 0 & - & 1 & 1 & 0.333 \\
\hline $\begin{array}{l}\text { Yếu tố ngoaại } \\
\text { cảnh khác }\end{array}$ & 0 & 0 & - & 0 & 0 \\
\hline
\end{tabular}

Tương tự, các yếu tố ảnh hưởng cũng được so sánh theo từng cặp giữa chúng và được gán cho các giá trị trọng số liên quan khác nhau. Các giá trị trọng số liên quan cho phép xếp hạng các yếu tố ảnh hưởng theo mức độ của tác động gây tổn thương đối với nhà cửa. Các kết quả đánh giá trọng số liên quan cho các yếu tố ảnh hưởng được trình bày trong các bảng 2 và 3 tương ứng với hai trường hợp thiệt hại về cấu trúc và thiệt hại do ngập lụt. Trong trường hợp sau, các yếu tố ảnh hưởng $\mathrm{d}$ (thiết kế) và $\mathrm{f}$ (kết cấu nền móng) không được xét đến vì chúng không chịu tác động của ngập lụt.

Bảng 2. Ma trận so sánh cặp đôi giữa các yếu tố ảnh hưởng đối với thiệt hại về cấu trúc

\begin{tabular}{|c|c|c|c|c|c|c|c|c|}
\hline $\begin{array}{l}\text { Thiệt hại } \\
\text { về cấu trúc }\end{array}$ & $\mathrm{m}$ & g & s & $f$ & $d$ & $\begin{array}{c}\text { Yếu tố } \\
\text { ngoại cảnh khác }\end{array}$ & Tỗng & $\begin{array}{c}\text { Trọng số } \\
\text { liên quan (=tồng/15) }\end{array}$ \\
\hline$m$ & - & 0 & 1 & 1 & 1 & 1 & 4 & 0.267 \\
\hline g & 1 & - & 1 & 1 & 1 & 1 & 5 & 0.333 \\
\hline $\mathrm{s}$ & 0 & 0 & - & 0 & 0 & 1 & 1 & 0.067 \\
\hline$f$ & 0 & 0 & 1 & - & 1 & 1 & 3 & 0.2 \\
\hline$d$ & 0 & 0 & 1 & 0 & - & 1 & 2 & 0.133 \\
\hline $\begin{array}{c}\text { Yếu tố } \\
\text { ngoại cảnh khác }\end{array}$ & 0 & 0 & 0 & 0 & 0 & - & 0 & 0 \\
\hline
\end{tabular}

Formatted: Font: $11 \mathrm{pt}$

Formatted: Position: Horizontal: Inside, Relative to: Margin

Formatted: Indent: First line: 0.63 
Bảng 3. Ma trận so sánh cặp đôi giữa các yếu tố ảnh hưởng đối với thiệt hại do ngập lụt

\begin{tabular}{|c|c|c|c|c|c|c|}
\hline Thiệt hại do ngập lụt & $\mathrm{m}$ & g & s & Yếu tố ngoại cảnh khác & Tổng & Trọng số liên quan (=tổng/6) \\
\hline $\mathrm{m}$ & - & 0 & 0 & 1 & 1 & 0.167 \\
\hline g & 1 & - & 0 & 1 & 2 & 0.333 \\
\hline s & 1 & 1 & - & 1 & 3 & 0.5 \\
\hline Yếu tố ngoại cảnh khác & 0 & 0 & 0 & 0 & 0 & 0 \\
\hline
\end{tabular}

Tổng hợp kết quả từ các bảng 1,2 và 3 ta được kết quả trình bày trong bảng 4 . Đối với cả hai tiêu chuẩn đánh giá, trọng số tổng cộng của mỗi yếu tố ảnh hưởng được tính bằng tích của trọng số tiêu chuẩn với trọng số liên quan của yếu tố ảnh hưởng đang xét. Kết quả tính trọng số tổng cộng của các

Bảng 4. Trọng số liên quan của các yếu tố ảnh hưởng

\begin{tabular}{|c|c|c|c|c|c|c|}
\hline & $\begin{array}{l}\text { Trọng số của } \\
\text { từng tiêu chuẩn }\end{array}$ & $\begin{array}{l}\text { Trong số liên } \\
\text { quan của m }\end{array}$ & $\begin{array}{l}\text { Trơng số liên } \\
\text { quan của g }\end{array}$ & $\begin{array}{l}\text { Trọng số liên } \\
\text { quan của s }\end{array}$ & $\begin{array}{c}\text { Trọng số liên } \\
\text { quan của f }\end{array}$ & $\begin{array}{c}\text { Trọng số liên } \\
\text { quan của d }\end{array}$ \\
\hline Thiệt hại về cấu trúc & 0.667 & 0.267 & 0.333 & 0.067 & 0.2 & 0.133 \\
\hline Thiệt hại do ngập lụt & 0.333 & 0.167 & 0.333 & 0.5 & 0 & 0 \\
\hline
\end{tabular}

Bảng 5. Trọng số tổng cộng của các yếu tố ảnh hưởng

\begin{tabular}{|c|c|c|c|c|c|}
\hline & Trọng số của m & Trọng số của g & Trọng số của s & Trọng số của d & Trọng số của f \\
\hline Thiệt hại về cấu trúc & 0.178 & 0.222 & 0.045 & 0.089 & 0.133 \\
\hline Thiệt hại do ngập lụt & 0.056 & 0.111 & 0.166 & 0 & 0 \\
\hline Tổng cộng & 0.234 & 0.333 & 0.211 & 0.089 & 0.133 \\
\hline
\end{tabular}

yếu tố ảnh hưởng được trình bày trong bảng 5 .

Từ các kết quả của bảng 5 và lưu ý công thức (2), có thể viết biểu thức tính mức độ tổn thương của tham số "Nhà cửa" dưới dạng:

$$
\mathrm{V}_{\mathrm{NC}}=0.234 \mathrm{~m}+0.333 \mathrm{~g}+0.211 \mathrm{~s}+0.089 \mathrm{~d}+0.133 \mathrm{f}
$$

Giá trị của các yếu tố ảnh hưởng $\mathrm{m}, \mathrm{g}, \mathrm{s}, \mathrm{d}$ và $\mathrm{f}$ được xác định theo các tiêu chuẩn phụ thuộc điều kiện cụ thể tại khu vực nghiên cứu. Công thức (3) được sử dụng để tính toán và thành lập bản đồ mức độ tổn thương thành phần do sóng thần gây ra đối với nhà cửa tại khu vực nghiên cứu.

\section{3. Đánh giá mức độ tổn thương cho tham số "Người"}

Mức độ tổn thương theo tham số "Người" có thể được hiểu như là khả năng bị thiệt hại về người do sóng thần gây ra tại khu vực nghiên cứu. Đối với tham số "Người", các yếu tố ảnh hưởng được xác định trong nghiên cứu này bao gồm: Mật độ dân số (d); Số lượng trẻ em, người trưởng thành và người già (thành phần dân số) (n); Giới tính (số lượng nữ) (g); Thu nhập bình quân (m).
Tất cả các dữ liệu về các yếu tố ảnh hưởng nêu trên phải được quy về một đơn vị tham chiếu thống nhất. Mức độ thiệt hại về người sẽ được tính toán ứng với đơn vị tham chiếu này. Đơn vị tham chiếu nhỏ nhất cho tổn thương về người có thể là một tòa nhà, nhưng nếu không có đủ số liệu chi tiết thì có thể chọn đơn vị tham chiếu lớn hơn, như một phường hay thậm chí một quận.

Đối với mỗi đơn vị diện tích đã chọn, các thông tin sau đây cũng cần biết: Mùa có mật độ dân số cao và thấp; Thời gian trung bình để sơ tán dân.

Công thức tính mức độ tổn thương của tham số "Người” sẽ có dạng:

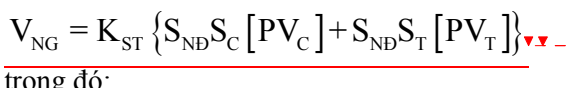

- $\mathrm{K}_{\mathrm{ST}}$ là hệ số liên quan đến thời gian trung bình để sơ tán dân trong phạm vi đơn vị tham chiếu đã chọn, với giả thiết là thời gian báo động sóng thần xầy ra trước 15 phút khi đợt sóng đầu tiên kéo đến. Các giá trị của hệ số $\mathrm{K}_{\mathrm{ST}}$ được đề nghị như trong bảng 6 , tuy nhiên giá trị này có thể được hiệu chỉnh tùy theo khả năng của hệ thống cảnh báo sóng thần;

\begin{tabular}{l} 
Deleted: $V_{\mathrm{NC}}=\mathrm{K}_{\mathrm{ST}}\left(\mathrm{S}_{\mathrm{ND}} \mathrm{S}_{\mathrm{C}}\left[\mathrm{PV}_{\mathrm{C}}\right]\right.$ \\
\hline Formatted: Left \\
\hline Deleted:
\end{tabular}

Formatted: Font: $11 \mathrm{pt}$

Formatted: Position: Horizontal: Inside, Relative to: Margin

Formatted: Indent: First line: 0.63 $\mathrm{cm}$ 
Bảng 6. Các giá trị đề nghị cho hệ số $\mathrm{K}_{\mathrm{ST}}$

\begin{tabular}{|c|c|c|}
\hline $\begin{array}{l}\text { Báo động } 15 \\
\text { trước khi sóng đến }\end{array}$ & $\begin{array}{l}\text { Thời gian sơ tán } \\
\text { trung bình (phút) }\end{array}$ & Giá trị $K_{E}$ đề nghị \\
\hline Khu vực 1 & $<5$ & 0.4 \\
\hline Khu vực 2 & $5-10$ & 0.6 \\
\hline Khu vực 3 & $10-15$ & 0.8 \\
\hline Khu vực 4 & $>15$ & 1 \\
\hline
\end{tabular}

- Giá trị $\mathrm{S}_{\mathrm{N}}$ phụ thuộc vào việc thời gian sóng thần tấn công là ngày hay đêm, với $\mathrm{S}_{\mathrm{N \boxplus}}=\mathrm{V}_{\mathrm{NC}} / 5$ (ban đêm, giả thiết là mọi người đang ở trong nhà), $\mathrm{S}_{\mathrm{N \boxplus}}=\mathrm{V}_{\mathrm{NC}} / 10+1 / 2$ (ban ngày, giả thiết là một nửa số dân đang ở trong nhà và một nửa ở bên ngoài).

- $\mathrm{S}_{\mathrm{C}}$ và $\mathrm{S}_{\mathrm{T}}$ là các hệ số chỉ mùa du lịch: Nếu đang trong mùa du lịch (lượng khách du lịch và mật độ dân cư cao) thì $\mathrm{S}_{\mathrm{C}}=1$ nếu sóng thần xẩy ra trong mùa du lịch; và $\mathrm{S}_{\mathrm{C}}=0$ nếu sóng thần xẩy ra lúc không phải mùa du lịch. Nếu đang không phải mùa du lịch (lượng khách du lịch và mật độ dân cư thấp): $\mathrm{S}_{\mathrm{T}}=1$ nếu sóng thần xẩy ra lúc không phải mùa du lịch; $\mathrm{S}_{\mathrm{T}}=0$ nếu sóng thần xẩy ra trong mùa du lịch.

- $\mathrm{PV}_{\mathrm{C}}$ là mức độ tổn thương của tham số "Người" trong đơn vị tham chiếu, được tính cho mùa có khách du lịch cao sử dụng công thức (4) và những yếu tố ảnh hưởng đã được xác định ở trên với chỉ số $\mathrm{C}$ :

$$
\mathrm{PV}_{\mathrm{H}}=\mathrm{w}_{1}\left(\mathrm{~d}_{\mathrm{C}}\right)+\mathrm{w}_{2}\left(\mathrm{n}_{\mathrm{C}}\right)+\mathrm{w}_{3}\left(\mathrm{~g}_{\mathrm{C}}\right)+\mathrm{w}_{4}\left(\mathrm{~m}_{\mathrm{C}}\right)
$$

Các trọng số được xác định bằng phương pháp phân tích đa tiêu chuẩn như trong trường hợp tham số môi trường xây dựng đã trình bày ở trên.

- Tương tự, $\mathrm{PV}_{\mathrm{T}}$ là mức độ tổn thương của tham số "Người" trong đơn vị tham chiếu, được tính cho mùa có khách du lịch thấp sử dụng công thức (4) và những yếu tố ảnh hưởng đã được xác định ở trên với chỉ số $\mathrm{T}$ :

$\mathrm{PV}_{\mathrm{L}}=\mathrm{w}_{1}\left(\mathrm{~d}_{\mathrm{T}}\right)+\mathrm{w}_{2}\left(\mathrm{n}_{\mathrm{T}}\right)+\mathrm{w}_{3}\left(\mathrm{~g}_{\mathrm{T}}\right)+\mathrm{w}_{4}\left(\mathrm{~m}_{\mathrm{T}}\right)$

Các công thức (4), (5) và (6) được sử dụng để tính toán và thành lập các bản đồ mức độ tổn thương thành phần về người do sóng thần gây ra tại khu vực nghiên cứu.

\section{4. Đánh giá nguy cơ bị tổn thương do sóng thần cho khu vực đô thị thành phố Nha Trang}

Phương pháp luận mô tả trong mục 3 được áp dụng thử nghiệm để đánh giá nguy cơ bị tổn thương do sóng thần tại một khu vực đô thị của thành phố Nha Trang. Khu vực nghiên cứu được lựa chọn nằm sát đường bờ biển, bao gồm 11 phường nội thành của thành phố Nha Trang với diện tích $7,9 \mathrm{~km}^{2}$ và tổng số dân là 163.885 người (hình 1 ).

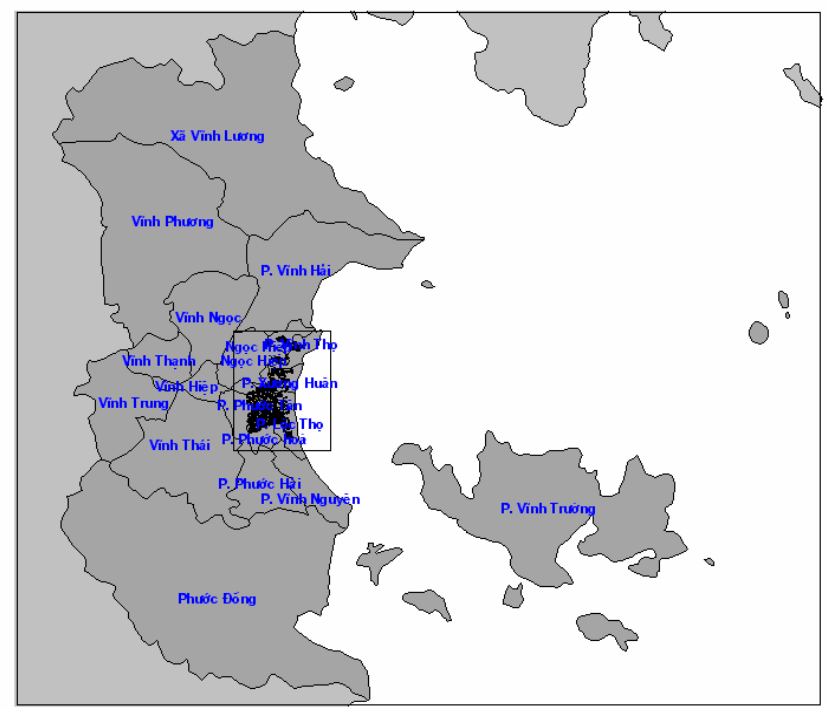

Hình 1. Vị trí khu vực nghiên cứu trên bản đồ thành phố Nha Trang (khung nhỏ)

Formatted: Font: $11 \mathrm{pt}$

Formatted: Position: Horizontal: Inside, Relative to: Margin

Formatted: Indent: First line: 0.63 


\subsection{Dũ liệu}

Các dữ liệu thuộc tính được sử dụng bao gồm hai loại chính là dữ liệu về dân số và dữ liệu về nhà cửa, trong đó các dữ liệu về dân số được khai thác từ các niên giám thống kê. Số liệu dân số chi tiết tới cấp phường được liệt kê trong bảng 7 [11].

Để khảo sát và thu thập các dữ liệu thuộc tính về nhà cửa, công tác thực địa được tổ chức quy mô tại khu vực đô thị sát bờ biển thành phố Nha Trang.

Các cán bộ khảo sát đã tiến hành khảo sát các công trình xây dựng trên toàn bộ các khu phố, các ngõ phố, các cụm dân cư trên địa bàn theo mẫu phiếu điều tra đã lập sẵn. Các dữ liệu thuộc tính về nhà cửa được nối kết với các dữ liệu không gian về nhà cửa, được số hóa từ ảnh nền Google ở tỷ lệ 1:2000.

Bảng 7. Dân số và diện tích các phường khu vực nghiên cứu năm 2009

\begin{tabular}{|c|c|c|c|}
\hline STT & Tên Phường & Dân số (người) & Diện tích $\left(\mathrm{km}^{2}\right)$ \\
\hline 1 & Vĩnh Phước & 20.662 & 1,09 \\
\hline 2 & Vĩnh Thọ & 14.823 & 1,3 \\
\hline 3 & Vạn Thắng & 13.012 & 0,28 \\
\hline 4 & Xương Huân & 17.873 & 0,61 \\
\hline 5 & Phương Sài & 13.284 & 0,29 \\
\hline 6 & Phước Tân & 13.103 & 0,48 \\
\hline 7 & Phước Tiến & 12.680 & 0,3 \\
\hline 8 & Phước Hòa & 14.461 & 1,12 \\
\hline 9 & Tân Lập & 16.242 & 0,59 \\
\hline 10 & Lộc Thọ & 12.861 & 1,47 \\
\hline 11 & Vạn Thạnh & 14.884 & 0,37 \\
\hline
\end{tabular}

Trên cơ sở các dữ liệu thu thập được, một cơ sở dữ liệu GIS được thành lập trên môi trường của phần mềm ArcView GIS. Ngoài các dữ liệu đầu vào được lưu trữ dưới dạng các bản đồ chuyên đề và bản đồ nền, cơ sở dữ liệu GIS còn lưu trữ cả các bản đồ kết quả.

\subsection{Xây dụ̂ng bản đồ mức độ tổn thương cho tham số "Nhà cửa"}

Phương pháp luận mô tả trong mục nhỏ 3.2 được áp dụng để xây dựng bản đồ mức độ tổn thương cho tham số "Nhà cửa" cho khu vực nghiên cứu. Các yếu tố ảnh hưởng được xác định theo một số tiêu chuẩn như sau:

- Giá trị của $m$ (vật liệu xây dựng) được xác định căn cứ theo kêt cấu của nhà cửa và hiện trạng chất lượng của công trình theo các số liệu khảo sát thực địa;

- Giá trị của $g$ (mô tả tầng trệt của ngôi nhà) được xác định dựa trên sự kết hợp các thông tin từ chức năng sử dụng và số tầng của ngôi nhà. Chức năng sử dụng của các ngôi nhà được phân ra thành 3 nhóm theo số tầng như sau (bảng \& 8 ): nhóm 1 chứa các nhà có số tầng $1,2,7 ;$ nhóm 2 chứa các nhà có số tầng là $3,4,8$; nhóm 3 chứa các nhà có số tầng là 5,6 .

- Giá trị của $\mathrm{s}$ (số tầng của ngôi nhà) được xác định thông qua số liệu khảo sát thực tế.

- Giá trị của $\mathrm{d}$ (thiết kế của ngôi nhà) được xác định theo bản đồ số hóa nhà cửa tại khu vực nghiên cứu.

- Giá trị của $\mathrm{f}$ (kết cấu móng nhà) được xác định dựa trên kết cấu của ngôi nhà và số tầng.

Bảng 8 liệt kê mối quan hệ phổ biến nhất giữa chức năng sử dụng nhà cửa và số tầng nhà tại khu vực khảo sát. Căn cứ vào các tiêu chuẩn đề ra, các yếu tố ảnh hưởng được gán các trị số như trình bày trong bảng 9.

\begin{tabular}{lc} 
Bảng 8 . Phân nhóm các chức năng sử dụng nhà cửa \\
\hline \multicolumn{1}{c}{ Chức năng sử dụng nhà } & Số tầng \\
\hline Quân đội & 2 \\
Tôn giáo (Nhà thờ, chùa) & 3 \\
Khách sạn, khách sạn + nhà ở & 4 \\
Nhà ở, Nhà ở + cửa hàng & 5 \\
Siêu thị, chợ & 6 \\
Nhà hàng, Cửa hàng dịch vụ & 7 \\
Trường học, viện bảo tàng & 8 \\
Cơ quan, văn phòng + nhà ở & \\
\hline
\end{tabular}

4.3. Xây dụ̂ng bản đồ mức độ tổn thương cho tham số "Người "

Để đánh giá mức độ tổn thương cho tham số "Người", trong nghiên cứu này chỉ xét trường hợp sóng thần xẩy ra trong mùa du lịch. Khi đó công thức (4) trở thành :

$$
\mathrm{V}_{\mathrm{NG}}=\mathrm{K}_{\mathrm{E}} \cdot \mathrm{S}_{\mathrm{N}} \cdot \mathrm{PV} \mathrm{V}_{\mathrm{C}}
$$

Do trong thực tế thời gian sơ tán dân có thể vượt quá 15 phút tính từ khi báo động nên các giá trị của $\mathrm{K}_{\mathrm{E}}$ được gán bằng 1 . Các tiêu chuẩn đánh

\begin{tabular}{l}
\hline Deleted: \\
\hline Formatted: Font: Italic \\
Formatted: Font: Italic \\
Deleted: 7 \\
Deleted: 9
\end{tabular}

Formatted: Font: Not Italic
Formatted: Font: $11 \mathrm{pt}$

Formatted: Position: Horizontal: Inside, Relative to: Margin

Formatted: Indent: First line: 0.63 
Bảng 9. Gán giá trị cho các yếu tố ảnh hưởng

\begin{tabular}{|c|c|c|c|c|c|}
\hline \multirow{2}{*}{$\begin{array}{l}\text { Yếu tố } \\
\text { ảnh hưởng }\end{array}$} & \multicolumn{5}{|c|}{ Giá trị đề nghị } \\
\hline & 1 & 2 & 3 & 4 & 5 \\
\hline $\mathrm{m}$ & Bê tông cốt sắt chịu lực & & $\begin{array}{l}\text { Gạch, gỗ, bê tông không } \\
\text { có cốt sắt }\end{array}$ & & Gỗ \\
\hline g & $\begin{array}{l}\text { Mă̆t tiền mở, không có các } \\
\text { đồ vật di động }\end{array}$ & & $\begin{array}{l}\text { Mặt tiền mở, có } \\
\text { các đồ vật di động }\end{array}$ & & Không có mặt tiền mở \\
\hline $\mathrm{s}$ & 5 tầng & 4 tầng & 3 tầng & 2 tầng & 1 tầng \\
\hline$f$ & Móng có trụ chống sâu & & Móng trung bình & & Móng đổ tràn trên mặt \\
\hline$d$ & $\begin{array}{l}\text { Chiều dài toà nhà thẳng góc } \\
\text { với bờ biển }\end{array}$ & & $\begin{array}{l}\text { Chiều dài toà nhà tạo } \\
\text { góc } 45^{\circ} \text { so với bờ biển }\end{array}$ & & $\begin{array}{l}\text { Chiều dài của toà nhà song } \\
\text { song với bờ biến }\end{array}$ \\
\hline
\end{tabular}

giá biểu thị các dạng thiệt hại do sóng thần gây ra trong trường hợp này sẽ bao gồm:

- Thiệt hại do ngập lụt; và Thiệt hại do các đồ vật trôi dạt gây ra.

Quá trình gán trọng số được thực hiện bằng phương pháp phân tích đa tiêu chuẩn theo các bước đã mô tả trong mục 3 . Biểu thức tương quan giữa các yếu tố ảnh hưởng nhận được trong trường hợp này có dạng:

$\mathrm{PV}_{\mathrm{C}}=0.317 \mathrm{~d}+0.317 \mathrm{c}+0.293 \mathrm{~g}+0.07126 \mathrm{~m}$

Từ $(7)$ và $(8)$ ta có:

$\mathrm{V}_{\mathrm{NG}}=\mathrm{K}_{\mathrm{E}} \cdot \mathrm{S}_{\mathrm{N \oplus}}(0.317 \mathrm{~d}+0.317 \mathrm{c}+0.293 \mathrm{~g}+0.07126 \mathrm{~m})(9)$

Như vậy, công thức tính mức độ tổn thương cho tham số "Người" trong trường hợp sóng thần tấn công ban ngày là:

$$
\begin{aligned}
& \mathrm{V}_{\mathrm{NGN}}=\mathrm{K}_{\mathrm{E}} \cdot\left(\mathrm{V}_{\mathrm{NC}} / 10+1 / 2\right)(0.317 \mathrm{~d}+ \\
& +0.317 \mathrm{c}+0.293 \mathrm{~g}+0.07126 \mathrm{~m})
\end{aligned}
$$

và trong trường hợp sóng thần tấn công ban đêm là:

$$
\begin{gathered}
\mathrm{V}_{\mathrm{NGD}}=\mathrm{K}_{\mathrm{E}} \cdot\left(\mathrm{V}_{\mathrm{NC}} / 10+1 / 2\right)(0.317 \mathrm{~d}+ \\
+0.317 \mathrm{c}+0.293 \mathrm{~g}+0.07126 \mathrm{~m})
\end{gathered}
$$

Các công thức (10) và (11) được sử dụng để tính mức độ tổn thương cho tham số "Người" trong hai thời điểm tấn công của sóng thần vào ban ngày và ban đêm. Các chương trình tính toán viêt trên ngôn ngữ Avenue được áp dụng cho từng đơn vị tham chiếu tương đương cấp phường tại khu vực nghiên cứu. Các giá trị $\mathrm{V}_{\mathrm{NGN}}$ và $\mathrm{VNG}_{\mathrm{NGP}}$ được xếp thành ba mức độ : cao, trung bình, thấp và được thể hiện trên bản đồ mức độ tổn thương về người do sóng thần.

\subsection{Các bản đồ kết quả}

Các bản đồ kết quả được thể hiện trên môi trường

đồ họa của phần mềm ArcView GIS. Trên hình 2 minh họa bản đồ mức độ tổn thương nhà cửa do sóng thần gây ra tại khu vực đô thị ven biển thành phố Nha Trang. Từ hình 2 , có thể nhận thấy nguy cơ tổn thương nhà cửa cao nhất tập trung tai khu vực cửa sông Cái, đặc biệt là trên cù lao Dê nằm sát biển, nơi tập trung nhiều nhà cấp 4 và phải đối mặt với sóng thần từ biển ập vào qua một cửa sông hẹp.

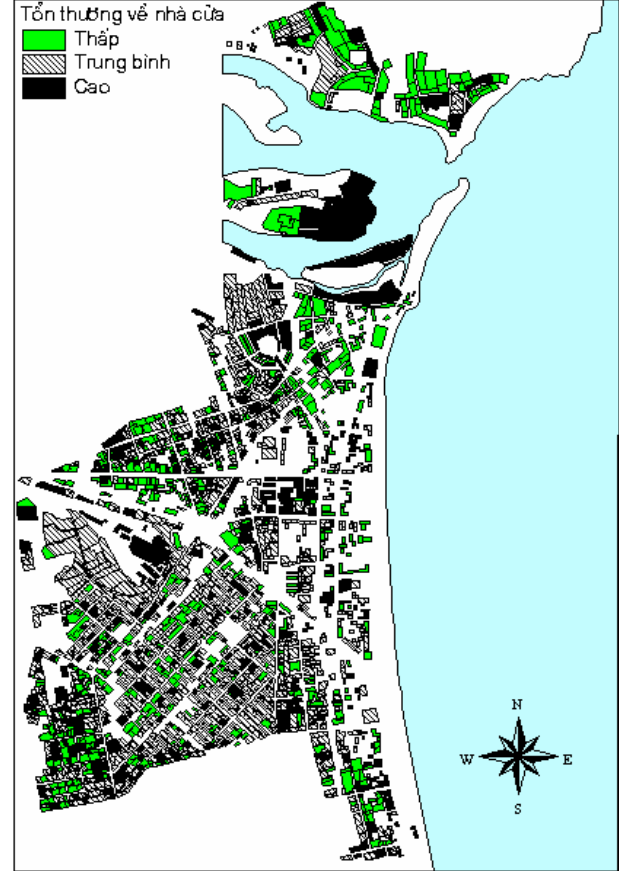

Hình 2. Bản đồ dự báo mức độ tổn thương nhà cửa do sóng thần gây ra tại khu vực đô thị ven biển thành phố Nha Trang
Formatted: Font: $11 \mathrm{pt}$

Formatted: Position: Horizontal: Inside, Relative to: Margin

Formatted: Indent: First line: 0.63 
Các bản đồ mức độ tổn thương về người do sóng thần gây ra tại hai thời điểm ngày và đêm được minh họa trên các hình $3 a$ và $3 b$ tương ứng. Các bản đồ trên hình 3 cho thấy nguy cơ thiệt hại về người tại hai thời điểm trong ngày là khác nhau.
Khu vực sát bờ biển, nơi tập trung nhiều khách sạn, nhà cao tầng và được gia cố tốt lại có mức độ tổn thương thấp hơn so với khu dân cư thuộc các phường Phước Hòa, Vạn Thanh,... nằm sâu hơn trong lục địa.
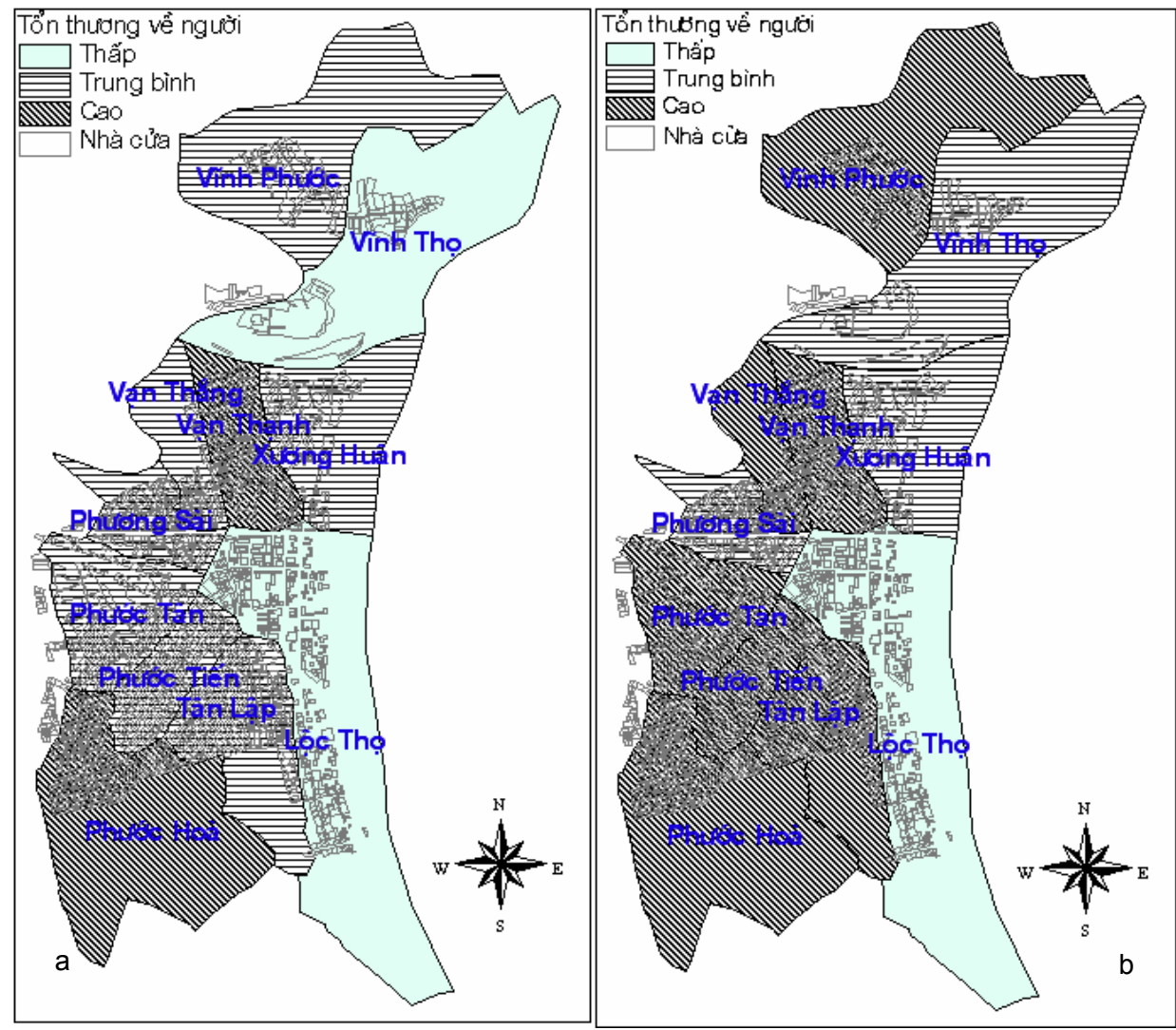

Hình 3. Bản đồ dự báo mức độ tổn thương về người do sóng thần gây ra cho khu vực đô thị ven biển thành phố Nha Trang cho hai trường hợp ban ngày (a) và ban đêm (b)

\section{Kết luận}

Bài viết đề xuất một phương pháp luận mới được sử dụng trong việc đánh giá mức độ tổn thương do sóng thần cho khu vực đô thị ven biển của Việt Nam. Phương pháp luận được xây dựng dựa trên lý thuyết phân tích đa tiêu chuẩn, cho phép đánh giá bán định lượng nguy cơ tổn thương của một khu vực đô thị nằm trong vùng bị ảnh hưởng của sóng thần. Uu điểm chính của phương pháp luận là đơn giản, linh hoạt đối với sự thay đổi các điều kiện cụ thể của khu vực nghiên cứu và cho phép sử dụng triệt để công cụ GIS trong mọi giai đoạn của quy trình đánh giá nguy cơ tổn thương. Quy trình có thể được áp dụng để đánh giá nguy cơ tổn thương cho một khu vực đô thị bất kỳ nằm trong vùng bị sóng thần đe dọa.

Phương pháp luận được áp dụng thử nghiệm cho một khu vực đô thị ven biển của thành phố
Formatted: Font: $11 \mathrm{pt}$

Formatted: Position: Horizontal: Inside, Relative to: Margin

Formatted: Indent: First line: 0.63 $\mathrm{cm}$ 
Nha Trang. Các kết quả cuối cùng được thể hiện trên môi trường GIS dưới dạng các bản đồ biểu th mức độ tổn thương về nhà cửa và người tại khu vực nghiên cứu. Các kết quả cho thấy tính ưu việt và triển vọng của hướng nghiên cứu đánh giá rủi ro sóng thần, đồng thời cũng cung cấp những thông tin bổ ích cho công tác cảnh báo sóng thần và hoạch định định chính sách phòng ngừa, ứng cứu và khắc phục hậu quả do sóng thần gây ra với cộng đồng ven biển.

\section{TÀI LIẸU DÂNN}

[1] Vũ Thanh Ca, 2008: Xây dựng bản đồ cảnh báo nguy cơ sóng thần cho các vùng bờ biển Việt Nam, Báo cáo tổng kết Đề tài cấp Bộ TNMT năm 2006-2008.

[2] Papathoma M. and Dominey Howes D., 2003: Tsunami vulnerability assessment and its implications for coastal hazard analysis and disaster management planning, Gulf of Corinth, Greece. Natural Hazards and Earth System Sciences, 3, pp.733-747.

[3] Post J.,Zosseder S., Weigcheider S., Sieinmetz T., Riedliger T., Strunz G., Mehl H., Dech S., Birkmann J., Gebert N., Anwar H. Z., and Harjono H., 2008: Risk assessment to low frequency - high impact coastal hazard in Indonesia : Integrating tsunami hazard and vulnerability assessment in the context of early warning. Proceedings of the International Conference on Tsunami Warning (ICTW), Bali, Indonesia, 12-14, 2008.

[4] Nguyễn Hồng Phuoong, Bùi Công Quế, Nguyễn Đình Xuyên, 2010: Khảo sát các vùng nguồn sóng thần có khả năng gây nguy hiểm tới vùng bờ biển Việt Nam. Tạp chí các Khoa học về Trái Đất, 32(1), 36-47.

[5] Bùi Công Quế, 2010: Nghiên cứu đánh giá độ nguy hiểm động đất và sóng thần ở vùng bờ biển Việt Nam và đề xuất các giải pháp phòng tránh. Báo cáo tổng kết đề tài nghiên cứu khoa học công nghệ cấp Nhà nước, Viện Vật lý Địa cầu.

[6] Trần Thị Mỹ Thành, 2009: Quy trình công nghệ đánh giá độ nguy hiểm sóng thần và cảnh báo nguy cơ sóng thần trên vùng ven biển Việt Nam (phù hợp yêu cầu của Hệ thống cảnh báo khu vực), Báo cáo tổng kết Đề tài độc lập cấp Viện $\mathrm{KH} \& \mathrm{CN}$ Việt Nam năm 2007-2008.

[7] Phạm Văn Thuc, 1995: Bước đầu đánh giá ảnh hưởng của sóng thần ở Biển Đông đến bờ biển Việt Nam, Các công trình nghiên cứu địa chất và địa vật lý biển, Nxb Khoa học và Kỹ thuật, Hà Nội.

[8] Nguyễn Đình Xuyên, 2007: Nghiên cứu đánh giá độ nguy hiểm động đất và sóng thần vùng ven biển Việt Nam, đề xuất các biện pháp cảnh báo và phòng tránh. Báo cáo tổng kết Đề tài cấp Viện KH\&CN Việt Nam năm 2005-2006.

[9] Department for Communities and Local Government: London, 2009 : Multi-criteria analysis: a manual, $161 \mathrm{p}$

[10] Italian Ministry for the Environment and Territory, 2005: CRATER (Coastal Risk Aanalysis of Tsunamis and Environmental Remediation. Final report extract.

[11] Bách khoa toàn thư mở Wikipedia, tiếng Việt. http://vi.wikipedia.org/wiki/Nha_Trang.

\section{SUMMARY}

\section{Assessment of tsunami vulnerability for an urban area of Nha Trang city}

In this paper a new methodology for tsunami vulnerability assessment for Vietnam is proposed. Based on Multi-Criteria analysis technique, the methodology allows semi-quantitatively assess the vulnerability of a coastal urban area being affected by future tsunamis. The advantage of the methodology is simplicity, flexible to the changes of conditions of reality and allowing application of a Geographic Information System (GIS). The procedure can be applied to any coastal zone under tsunami threat.

The methodology is pilot tested in a coastal urban area of Nha Trang city. The results are presented within a GIS in terms of vulnerability maps for such aspects as building environment and population. The results show prospects in the new direction of tsunami risk study in Vietnam and provide important implications for coastal risk assessment, resource allocation as well as disaster management planning.

Formatted: Font: $11 \mathrm{pt}$

Formatted: Position: Horizontal: Inside, Relative to: Margin

Formatted: Indent: First line: 0.63 